\title{
EXAMINATION OF IMPACT OF ECONOMIC POLICY ON QUALITY OF LIFE IN REGIONS OF SOME EUROPEAN COUNTRIES WITH GLOBAL PERSPECTIVE
}

\author{
Jozsef Kaposzta, Balazs Illes, Henrietta Nagy \\ Szent István University, Hungary \\ dekan@gtk.szie.hu, illesbalazs@hotmail.com,nagy.henrietta@gtk.szie.hu
}

\begin{abstract}
Based on the current information available, there is no solid research that would combine quality of life with economic performance and corporate business, so in our paper we have identified the most commonly used factors of quality of life and categorized them according to their background. Quality of life is a responsibility of the individuals and the society, thus we should investigate them at both levels. Moreover, we presumed that the weight of these factors are changing from time to time, and that change goes along with the effect of the governance on economy what is driven by the evolution of the different state theories applied. During the drawing up of the research plan we have faced the problem of defining such sectors in a region, which generates the greatest positive effects on well-being, and it is really hard to describe what really the enhancement of the quality of life is. In our research we were also curious if there are any models that diagnose what is good for the people in a region from economic and non-economic point of view. In order to get proper knowledge on that field we tried to define and separate the categories of quality of life, well-being and welfare and also to show their embeddedness and relations to each other. In our research we have made a comprehensive overview on the literature about wellbeing, welfare, quality of life, and in addition to the static description we think it is important to investigate the underlying factors of quality of life and also to have a view on the differences of developed and emerging countries. The target area of our research is the regions of Europe, with special focus on the European Union.
\end{abstract}

Keywords: quality of life, regional development, income inequality, welfare, well-being.

\section{Introduction}

The differentiation and interpretation of the elements of quality of life is a complex and comprehensive task that should be started with the distinctions of the terms we use. Quality of life has been investigated since the antiquity and one of the comprehensive studies about the topic has been performed by Aristotle in his work Nicomachean Ethics, where he already made the distinction of objective and subjective elements of the quality of life. Although Aristotle's thoughts have influenced the whole European culture and his principle of eudaimonia (happiness as the greatest good) can be recognized in some processes of the economy as well, his works have given us only a theoretical approach to quality of life. The need for scientifically provable methods in social sciences rose in the $17^{\text {th }}$ century and the first statistical economical researcher of the topic is supposed to be Sir William Petty. In his works [1] he investigated the value theory, monetary issues, taxation and he supposed to be also the first researcher calculating national income in England. Accounting the wealth of a nation is one fundamental approach that could be also used to estimate quality of life and therefore we also consider this part and later on in this paper we will refer to any kind of material wealth connected to quality of life as welfare. Without understanding another major factor underlying the idea of economics the role of welfare would be hardly understandable. The avoidance of suffering and maximization of pleasure as a drive of humans was introduced by Jeremy Bentham [2] as utilitarism and has been investigated in the past more than two centuries by several authors [3-4]. Utilitarism as an underlying principle will be adopted in our approach as well and will be interpreted later in the paper. Another vast topic in the quality of life studies is in relation with happiness researches, which have different approaches and can hardly get to a common point in questions like personal subjective happiness [5-7]. In this paper for the subjective, non-material elements of quality of life we will use the term of well-being, which is considered by some researchers as happiness but in our approach well-being is a larger pile than happiness, and it can be deducted into several subcategories, which could be investigated separately, while some of aspects of happiness are considered intangible from our point of view. Without any universal approach or synthesis of happiness research we consider it as one element of well-being and we are not investigating it because of its subjective-affective elements.

Warr [8] made another distinction and separated positive emotional state, mood, emotions and well-being, but this kind of clusterization is not necessary for our research. 
As a summary, we are interested in the research of quality of life, which consists of material elements referred in the paper as welfare and non-material elements as well-being. The most important parts of quality of life are those, which have long-term cognitive and affective effect and general impact on the individual and the society and which are perceived and experienced, and affect several areas of life. The reliability and quantifiability of the results are also a key point and therefore we suppose that welfare is one of the key elements of quality of life. In the next subchapter we would like to introduce different approaches and finally a summary according to the elements of quality of life. Our research goal was to have a broad overview of the influencing factors and the related indices used to analyse quality of life mainly in European countries. To analyse that, we firstly had to summarize literature about quality of life and later analysis of the underlying principles and factors that are used in these models to define and analyse well-being and welfare. Beacause of proximity to the European countries we choose to use the data from EUROSTAT to make our own researches in not only the EU but also some candidate and EFTA countries. According to some methodological problems what we saw after analyzing the sample (like the missing parallel data for knowledge based on labor market clustering or unreliable changes from one employment category to another) we had to deselect some countries from the original sample of 33 and finally only 20 country remained for analysis. Although, if we have found some evidence of globally acceptable phenomena in our literature review, we also shared these with the facts that are relevant only for Europe.

\section{Materials and methods}

The different approaches to quality of life have been discussed among the researchers with various backgrounds and some of the ideas can lead to unsolvable problems. If we accept the Nordenfelt's approach [9], an individual can be considered content with the quality of life if her/his needs are satisfied fully by her/his actual circumstances. This means that every individual criteria system (needs) combined with the various actual conditions create billions of combinations, which cannot be on the social level, which was described by Arrow [10] in his impossibility theorem or by Olson [11] in his work of logic of collective action. Based on these simple assumptions we can say that there will not be any universal action that will enhance the quality of life for every person but some parts of the system, mainly those connected to welfare, can be influenced by economic policies. According to that we suggest that decision-makers should focus on the variable elements that can be changed with conscious economic political actions.

In order to have a broad perspective of the topic we investigated the different methods and indices, which measure fully or partly quality of life, which are the following ones:

- Human Development Report and Human Development Index (HDI);

- World Happiness Report (WHR);

- OECD Better Life Initiative (BLI);

- Gross National Happiness;

- Genuine Progress Indicator;

- Where to born index;

- Happy Planet Index;

- European Quality of Life Survey (EQLS).

According to the space limitations of a scientific paper we only focused on the indices, which brought us the most relevant findings and were used to have a better understanding about the phenomena of quality of life, but in our further studies we would like to share a more comprehensive comparison of all the indices. When we accept the Noll's approach [12], the main goal of indices is to represent the actual state and changes of quality of life on an individual and social level. The investigated indices and tools are fully or partly able to measure almost every aspect of quality of life, but the number of the variables used in the models differs seriously. The analyzed models always consider post-material parts of life as well in order to have a better approach to quality of life. We selected some of the major studies to give an overview about our findings.

\section{Human Development Report - Human Development Index}

One of the most important researches was performed by the UN in 1990 under the United Nations Development Programme (UNDP) published as the Human Development Report (HDR) [13]. The 
research team defined the theory and concept of human development and also built the structure of measurements. It also has given a summary about the global changes in human development between 1960 and 1990 in order to emphasize strategical challenges of that era. The third chapter of the HDR investigated the connection between human development and welfare. Later on several other reports tried to research this topic after twenty years of the initiative [14-18]. The HDR acknowledges the importance of welfare on human development but does not consider it as an automatic effect [13] The heritage of the original HDR continued and the new reports were concentrating on the geographical distribution of welfare and the shift of human development from north to south. The HRD investigates not only the actual income, but its distribution among the society as well [13]. In the report the GINI coefficient is always higher then 0.5 and therefore the report says that there is a negative connection between income inequality and human development [13].

\section{Gallup World Poll and World Happiness Report (WHR)}

Using the data of the Gallup World Poll the so called World Happiness Report (created first in 2012) used the subjective opinions of the ones involved in the survey to make its revision and suggestions about the topic. Gallup made the survey in 160 countries in the world representing $98 \%$ of Earth inhabitants. The structure of the study was designed by well-known researchers of the topic Daniel Kahnemann, Ed Diener and John Helliwell. The core questions used 11 basic elements (such as health, welfare, economic situation, labor, etc.) and one complementary. The participants (1000 person representative sample from the citizens above the age 15) were asked to evaluate their situation on an 11 scale Cantrill ladder. They separated the evaluation of the present situation from the past and they measured actual and general well-being as well [19]. The United Kingdom Office for National Statistics (ONS) also used data about the near-past and the present, while the European Union survey [20] interpreted well-being on a larger time scale. All the results of these findings showed similarities with the WHR and different elements of very high correlation $(r=0.94)$ with the Gallup poll [15]. Of course, there are several different findings as well, which are interpreted with similar factors (for example, income inequality). The quality of life and the deviation in the different regions could be unfold by six major elements, which are responsible for the $95 \%$ of the deviations [15]. According to that knowledge we can say that these factors can be considered as the most important ones in the quality of life studies, which are the following: per capita gross domestic product, life expectancy, social support (the feeling that I can count on someone in trouble), corruption perceived, and the frequency of generosity and freedom of choice in life. The most influential external factors are income, work, community, quality of governance and the categories of religion and values. The most important internal or personal factors are mental and physical health, family experiences, education, gender and age [15]. By some factors there is a very strong bilateral relation, for example, between health and subjective well-being.

\section{OECD Better Life Initiative and Index}

The Commission on the Measurement of Economic Performance and Social Progress (CMEPSC) also known as the Stieglitz-Sen-Fitoussi Committee was established in 2008. The Eurobarometer results showed that the European citizen perceives quality of life in a much broader sense than just welfare [20] and because of that the commission supported the creation of a new methodology in order to handle the new challenges. As a result of these ideas the OECD Better Life Initiative (BLI) has started to count the generally measurable and relevant factors and data sources, which could be used to help the monitoring and the decision-making processes as well. The initiative declared two different steps one the creation of the Your Better Life Index (YBLI) (published first in 2011) and the biannual study "How's Life" report [18]. The interactive "Your Better Life Index (BLI)" project helps the ones interested in the topic compare the quality of life elements with eleven different factors.

These factors are just recommendations, they could be left out from the studies or their weight can be modified in order to make them flexible. The specialty of BLI is that its focus is more on the end results and not on the input side of quality of life. The interactive tool makes us able to use our own preferences in a comparison and with that we can compare regions as well.

Between the quantitative income situation and the subjective satisfaction of the individual there are quite often huge gaps and with a flexible tool we can adjust it to our needs. The relation of subjective and objective welfare has been investigated by several authors [21-22]. Inglehart and 
Klingemann [23] accepted that the individuals with higher income have better quality of life, but the effect of welfare on well-being was assessed as $4 \%$. If we accept the theory of Veenhoven [24], we can also see that the importance of welfare changes with the absolute income conditions, so in countries with lower welfare welfare is overrated, while in rich countries its importance reduces significantly. During the first WHR researchers used a simple regression model to show the relation between the logarithm of per capita GDP and average quality of life and they found a significant relation between them [25]. The report of 2013 stated that $47 \%$ of national differences in quality of life can be interpreted by differences of welfare [16]. Just as in the income, in well-being a huge difference in dispersion has been perceived, although the dispersion of incomes is $42 \%$, while the dispersion of happiness is only $22 \%$. If we check the happiest and the less happy countries we will see that the happiest have 40 times higher income than the ones with the less happy conditions [15].

To define the relation of the factors new factors were involved into the model [15]. If quality of life is segmented into different factors and we would like use a regression coefficient to show the weight of income, we will see that the regression coefficient $\beta$ is relatively high $(\beta=0.81)$ for general well-being, positive emotions in the near past have a medium impact $(\beta=0.40)$, negative emotions in the near past do not play a high role $(\beta=-0.08)$. The report and the survey have been conducted with the involvement of 153 countries with high level of confidelity. [15]. The determination coefficient $R^{2}$ was $65 \%$ between the income and general satisfaction with life, so income has a significant explanatory power on quality of life. Later on they involved more and more factors (health, education, social support, experiencing freedom, corruption, divorce), but now the sample was provided only from 139 countries. With the involvement of more factors into the equation $R^{2}$ it has become $80 \%$, so all the elements explained $80 \%$ of the changes of quality of life, while income itself lost from its significance and the correlation coefficient $\beta$ becomes equal with 0.28 . For our research, the results of the European Social Survey have also great significance [15] where they found similar results. If only per capita GDP is involved into the factors, $\beta$ equals 0.84 , while with the new factors, $\beta$ is reduced to 0.36-ra. With all this information we could say that welfare plays an important role in the world's and Europe's quality of life. Unfortunately, there is no evidence about the correlation between the factors that were involved in these studies, so we cannot predict how, for instance, only emerging welfare will help on health, education or on other factors. The WHR has been created not just only to investigate the questions mentioned above, but also to serve as a kind of the decision-making and supporting system that we think can be integrated with other topics of regional studies as well.

\section{Results and discussion}

The goal to summarize the different indices was to have an overview about the topic and also to create subcategories like objective or subjective, material or non-material elements. From the quantitatively observable elements the material parts belong to the discipline of economics, therefore it is important to investigate the factors that have influence on these material welfare elements. Our main goal is to create a bridge between the material elements and economic policy and to count the beneficial effects that are generated by the specific actions performed by the nation or the local government. The private company efforts to enhance the quality of life can be inserted into the model. If we consider all the actors, we can create a comprehensive model that shows the links between the factors of a regional economy and the different parts of quality of life. According to our previous and ongoing researches we are highly focusing on knowledge intensity in the different sectors and we would like to connect knowledge intensive sector concentration with welfare to see their interrelations.

As a summary of our review we can state the following findings.

- There is no common quality of life concept and beside the objective and material elements, subjective non-material elements are always considered.

- The surveys that are focusing on the subjective elements (instantaneous positive and negative feelings and general life satisfaction) always consider material elements (wealth, income, housing, etc.) and their correlations with the subjective ones [15;20].

- The role of objective elements (mainly GDP or GNI) in global comparison studies are argued from different approaches, but most of the researchers agree that they can enhance quality of life according to regional specialties and differences. 
- Beside welfare based studies there are several others that are focusing on the relativity of quality of life, but the comparability of these studies is debatable.

- Most of the indices consider absolute and relative differences in welfare and they are also focusing on the effect of material inequalities in a region [13-16].

- The indices consider input reliability (statistical methods and data quality), but more and more emphasis is given to the outputs as a basis for decision-making functions.

- Among the investigated eight models seven consider some kind of welfare index, mainly GDP per capita on power purchasing parity. In order to have a more punctual picture of household welfare material inequality and individual consumption are also considered in some models.

After having an overview about our different findings we can state that the main quality of life models consider material welfare. The message of our findings is that decision-makers can focus on elements, which can enhance regional welfare and some elements of quality of life can be influenced indirectly with economic policies. In our further studies we will try to have an overview about the different sectors that can contribute to regional quality of life. To see what kind of tasks and tools are already given in the governance hand we created Table 1. as a summary.

Table 1

Economic and legistlative objectives and administration tools and tasks

\begin{tabular}{|c|c|}
\hline Objectives & Tools and tasks \\
\hline Easing cyclical fluctuations in economy & $\begin{array}{c}\text { Normative - legal, moral, ethical, technical and } \\
\text { other - control }\end{array}$ \\
\hline Containing inflation & $\begin{array}{c}\text { Regulatory law: licensing, obligation, prohibition, } \\
\text { supervision, inspection, sanctions }\end{array}$ \\
\hline Employment and unemployment rate & $\begin{array}{c}\text { Direct economic activity of the state or local } \\
\text { governments }\end{array}$ \\
\hline $\begin{array}{c}\text { Preservation of international commodity and } \\
\text { money market balance }\end{array}$ & Fiscal and monetary instruments \\
\hline $\begin{array}{c}\text { General preservation of values (life, limb, } \\
\text { property safety) }\end{array}$ & Wage and income control \\
\hline $\begin{array}{c}\text { Building social network } \\
\text { Social policy objectives to ensure the economic } \\
\text { background }\end{array}$ & Economic planning \\
\hline $\begin{array}{c}\text { Coordination of economic activities in the } \\
\text { common interest }\end{array}$ & $\begin{array}{c}\text { Not legally formalized tools: mobilization, } \\
\text { campaigning, lobbying, education }\end{array}$ \\
\hline
\end{tabular}

From the different objectives we would like to emphasize that the social policy objectives combined with the coordination of economic activities are highly related to the quality of life and with economic planning and direct involvement with sectoral subsidies regional welfare and well-being could be improved.

\section{Conclusions}

In our researches we would like to investigate the effect of regional concentration of specialized sectors, especially the ones with high added value and knowledge intensity, because we assume that these circumstances highly influence regional welfare. We found a significant amount of evidence to select the factors that should be analyzed to continue our researches in the topic of quality of life and also to narrow our interests to material factors of welfare. We also used our review to see the limitations of the quality of life researches like the ones we observed with the labor data later on in our analysis. Data on concentration is a basis for cluster analysis, although direct or primary cluster studies such as the European Cluster Observatory database can be also used for this task. After our comprehensive study we would like to gather all the necessary information to analyze the beneficial effects of local industrial and service concentrations in order to know, which sector should be a focus as a key for regional development and regional quality of life enhancement projects in the future. Business clusters focusing on these sectors could play a great role on local quality of life enhancement projects and therefore their activities should be handled as a complex question of policies. From the 
results of the Gallup World Poll and the WHR in this study we emphasized the correlation and connection between welfare and quality of life and we think that this approach could be a basement for a decision-making system where regional policies, the actors of the economy and the citizens could be involved. These findings were used as a basis for our studies and they helped us manifest our interest in our research topics as well.

\section{References}

1. Petty W. Political Arithmetik. Reprinted in Hull, C.H. 1899. The Economic Writings of Sir William Petty. Cambridge University Press. Cambridge, 1690.

2. Bentham J. Principles of Morals and Legislation. 1781, [online][11.12.2017] Available at: http://www.econlib.org/library/Bentham/bnthPMLCover.html.

3. Pigou A.C. The Economics of Welfare. Macmillan, London, 1924.

4. Sen A. The Concept of Development In: H. Chemery and T.N. Srinivasan (szerk): Handbook of Development Economics, Volume 1, , Elsevier Publisher B.V., 1988, pp.10-25

5. Scanlon, T. What Do We Owe to Each Other?, Boston: Harvard: Belknap Press, 1998.

6. Seligman M. Flourish: A New Understanding of Happiness and Well-being - and How to Achieve Them, Boston \& London: Nicholas Brealey, 2011.

7. Kraut, R., (2011): Against Absolute Goodness, New York: Oxford University Press.

8. Warr P. Work, happiness and unhappiness. New Jersey:Lawrence Erlbaum Associates Publishers, 2007.

9. Nordenfelt L. Quality of life, Health and Happiness, Hants, England: Avebury Ashgate Publishing, 1993.

10. Arrow K.J. Social Choice and Individual Values, New York: Yale University Press, 1951. ISBN 0-300-01364-7

11. Olson M. The Logic of Collective Action: Public Goods and the Theory of Groups (Revised ed.). Harvard University Press, 1971. ISBN 0-674-53751-3

12. Noll H-H. Social Indicators and Quality of Life Research:Background, Achievements and Current Trends In: Genov, Nicolai (szerk) Advances in Sociological Knowledge over Half a Century. Paris: International Social Science Council, 2002.

13. Human Development Report (1990) - Published for the United Nations Development Programme - Oxford - Oxford University Press

14. Human Development Report (2015) - 'Work for Human Development' (2015 Link: report.hdr.undp.org

15. World Happiness Report 2012 - Eds: Helliwell, J. - Layard R. - Sachs J. ISBN: 978-0-99685130-5 Link: worldhappiness.report/ed/2012

16. World Happiness Report 2013 - Eds: Helliwell, J. - Layard R. - Sachs J. ISBN: 978-0-99685130-5 Link: worldhappiness.report/ed/2013

17. OECD (2011): Measuring Progress and Well-Being OECD Secretary General 24th May 2011 OECD Forum.

18. OECD (2013a) Guidelines on Measuring Subjective Well-Being (C OECD 2013.

19. Gallup World Poll - World Poll Questions (2006) - Washington: Gallup Poll Consulting University Press Washington [online][11.12.2017] Available at:

http://media.gallup.com/dataviz/www/WP_Questions_WHITE.pdf

20. Eurofound (2012), Third European Quality of Life Survey - Quality of life in Europe: Impacts of the crisis, Publications Office of the European Union, Luxembourg.

21. Allardt E. Having, loving, being: An alternative to the Swedish model of welfare research', In: M. Nussbaum and A. Sen. (szerk.), The Quality of Life, Oxford: Clarendon Press, 1993, pp. 88-94.

22. Erikson R., Hansen E.J., Ringen S., Uusitalo H. The Scandinavian way: Welfare state and welfare research. London: ME Sharpe Inc., 1986.

23. Inglehart R., Klingemann H.D. Genes, Culture, Democracy and Happiness, In: Diener E. Suh E.M. Subjective Well-being Across Cultures. Camebridge, MA: MIT Press, 2000, pp. 165-183

24. Veenhoven R. Happiness in nations: Subjective appreciation of life in 56 nations 1946-1992. Rotterdam, The Netherlands: Risbo, 1993.

25. Deaton A. Income, Health, and Well-Being around the World: Evidence from the Gallup World Poll. Journal of Economic Perspectives, 22(2), 2008, pp. 53-72. 